\title{
Efeito da evisceração retardada sobre a conservação de carne de aves (Gallus domesticus) resfriada
}

\author{
Effect of retarded evisceration on conservation of poultry (Gallus \\ domesticus) refrigerated meat
}

\author{
Carlos Alberto Magioli ${ }^{1}$, Henrique Silva Pardi², Mônica Queiroz de Freitas ${ }^{3}$ e Sérgio Borges Mano ${ }^{3}$
}

\begin{abstract}
Resumo
Analisou-se 60 amostras de carcaças de frangos, abatidos em matadouro industrial, divididos em dois lotes de 30. No primeiro tratamento, adotou-se um processamento normal de matança e no segundo, houve um retardo na evisceração de 40 minutos. Realizou-se análises microbiológicas (CBHAM - contagem de bactérias heterotróficas aeróbias mesófilas e CBHAP - contagem de bactérias heterotróficas aeróbias psicrotróficas) e físico-químicas ( $\mathrm{pH}$, tempo de filtração e BVT - bases voláteis totais), no $1^{\circ}$ e $7^{\circ}$ dias após o abate, com as carcaças conservadas à temperatura de $3 \pm 1^{\circ} \mathrm{C}$. Os valores médios encontrados no primeiro e segundo tratamento no primeiro dia, foram respectivamente: $5,1 \times 10^{3} \mathrm{UFC} / \mathrm{g}$ e $3,3 \times 10^{3} \mathrm{UFC} / g$ para CBHAM; $6,3 \times$ $10^{3} \mathrm{UFC} / \mathrm{g}$ e 4,4 $\times 10^{3} \mathrm{UFC} / \mathrm{g}$ para CBHAP; 5,59 e 5,52 para $\mathrm{pH} ; 6,77$ minutos e 6,43 minutos para tempo de filtração; $10,38 \mathrm{mgN} / 100 \mathrm{~g}$ e 10,46 mgN/100g para BVT. No $7^{\circ} \mathrm{dia}$, os valores médios no primeiro e segundo tratamento, foram respectivamente: $2,1 \times 10^{4} \mathrm{UFC} / \mathrm{g}$ e $1,1 \times 10^{5} \mathrm{UFC} / \mathrm{g}$ para CBHAM; $2,5 \times 10^{5} \mathrm{UFC} / \mathrm{g}$ e $4,0 \times 10^{5} \mathrm{UFC} / \mathrm{g}$ para CBHAP; 5,51 e 5,59 para $\mathrm{pH} ; 10,13$ minutos e 10,55 minutos para tempo de filtração; 10,48 mgN/100g e 10,33 mgN/100g para BVT. O teste estatístico, através da análise de variância, demonstrou que nos dois tratamentos houveram diferenças significativas entre $01^{\circ}$ e $7^{\circ}$ dia, na prova de filtração e na CBHAP. Não foram encontradas diferenças significativas entre os dois tratamentos para nenhuma das análises realizadas.
\end{abstract}

Palavras-chave: carne de frango, evisceração retardada, conservação

\section{Introdução}

O processo normal de abate de aves, em sistema contínuo, requer um tempo em torno de 45 minutos. Nos mata- douros podem, eventualmente, ocorrer interrupções frente às quais, o Inspetor Médico Veterinário carece de dados técnicos, que possam auxiliar na avaliação das carcaças, principlamente aquelas que no momento da parada não se encontram evisceradas.

As Normas Higiênico-Sanitárias e Tecnológicas para Construção e Funcionamento de Matadouros de Aves (Departamento Nacional de Produção Animal, 1988), destacam que, a partir da sangria, todas as operações deverão ser realizadas continuamente, não sendo permitido o retardamento em nenhuma de suas fases, até a entrada das carcaças nas câmaras frigoríficas.

Para Asdrubali et al. (1969) e Bartels (1971), a evisceração deve realizar-se no menor tempo possível após a morte, pois os retardos eventuais causam alterações das carnes, devido a passagem de germes intestinais para a cavidade abdominal e músculos.

Albuquerque et al. (1979), trabalharam com frangos eviscerados e não eviscerados mantidos à temperatura de $0^{\circ} \mathrm{C}$ por um período de 96 horas. As análises microbiológicas, determinação de pH e prova de degustação não demonstraram diferenças significativas entre os dois lotes trabalhados.

Benoff et al. (1984) e Riedel (1987), indicaram que qualquer retardo na evisceração, permite a proliferaçẵo microbiana, sendo uma das causas da putrefação em aves.

O presente trabalho visa avaliar as condições de conservação, por um período de sete dias, de carcaças de frangos submetidas a um retardo de 40 minutos na evisceração, quando comparadas com aquelas abatidas em condições normais, com o objetivo de fornecer subsídio científico, para a elaboração de uma padronização dos critérios de atuação dos serviços de inspeção sanitária de aves.

\footnotetext{
'Médico Veterinário (MS) Ministério da Agricultura e Reforma Agrária (MAARA).

2Professor Adjunto IV (MS) Universidade Federal Fluminense (UFF), Faculdade de Veterinária, Departamento de Tecnologia dos Alimentos - CEP: 24230340 Niterói/RJ.

3Professores Assistentes II (MS) Universidade Federal Fluminense (UFF), Faculdade de Veterinária, Departamento de Tecnologia dos Alimentos - Niterói/RJ.
} 


\section{Material e Métodos}

Foram utilizadas 60 carcaças de frango, sendo separadas em 2 lotes de 30 carcaças. O primeiro lote foi colhido após as operações normais de matança, ao final da fase de embalagem. O segundo lote, foi retirado da nórea após a operação tecnológica de depenagem, quando era simulada uma parada no processo por um período de 40 minutos. Após esse período, as aves eram recolocadas na nórea e seguiam o fluxo normal de abate e colhidas ao final da fase de embalagem. Os lotes devidamente identificados, eram transportados e conservados à temperatura de $3 \pm 1^{\circ} \mathrm{C}$. As amostras eram analisadas no primeiro e sétimo dias após a matança, utilizando-se para cada dia, um dos lados da musculatura peitoral. Procedeu-se às seguintes provas físico-químicas: Prova de filtração (Departamento Nacional de Produção Animal, 1981), medição do pH através do método potenciométrico e Bases Voláteis Ttotais, através da técnica de microdifusão em placa de Conway. (Departamento Nacional de Produção Animal, 1981). Foram realizadas as análises microbiológicas de contagem de Bactérias Heterotróficas Aeróbias Mesófilas (CBHAM) e contagem de Bactérias Heterotróficas Aeróbias Psicrotróficas (CBHAP), seguindo-se a técnica descrita pelo LANARA (Departamento Nacional de Produção Animal, 1981). Os resultados obtidos foram tratados estatisticamente, através da análise de variância, entre os tratamentos e dias de análise $\left(1^{\circ}\right.$ e $\left.7^{\circ}\right)$. Estudou-se ainda, a diferença entre médias, através do Teste de Duncan.

\section{Resultados}

Os resultados médios para contagem microbiológica, $\mathrm{pH}$, filtração e bases voláteis totais, bem como o desvio padrão obtidos para as aves abatidas em condições normais e para as submetidas ao retardo na evisceração, podem ser apreciados nas Tabelas 1 e 2 respectivamente.

A análise de variância dos resultados obtidos para CBHAM, pH e BVT, não mostrou-se significativa $(p>0,05)$ tanto em relação aos dias $\left(1^{\circ}\right.$ e $\left.7^{\circ}\right)$, quanto aos tratamentos (normal e retardado).

Tabela 1 - Média de Contagem de Bactérias Heterotróficas Aeróbias Mesófilas (CBHAM) e Psicrotróficas (CBHAP), pH, Bases Voláteis totais (BVT) e tempo de Filtração no $1^{\circ}$ e $7^{\circ}$ dias da conservação de aves com evisceração normal.

\begin{tabular}{|c|c|c|c|c|c|c|c|c|c|c|}
\hline & \multicolumn{2}{|c|}{ CBHAM } & \multicolumn{2}{|c|}{ CBHAP } & \multicolumn{2}{|c|}{$\mathrm{pH}$} & \multicolumn{2}{|c|}{ BVT } & \multicolumn{2}{|c|}{ Filtração } \\
\hline & $1^{\circ}$ & $7^{\circ}$ & $1^{\circ}$ & $7^{\circ}$ & $1^{\circ}$ & $7^{\circ}$ & 10 & $7^{\circ}$ & 10 & $7^{\circ}$ \\
\hline$x$ & $5,1 \times 10^{3}$ & $2,1 \times 10^{4}$ & $6,3 \times 10^{3}$ & $2,5 \times 10^{3}$ & 5,59 & 5,61 & 10,38 & 10,48 & 6,77 & 10,13 \\
\hline STD & $7,9 \times 10^{3}$ & $6,1 \times 10^{4}$ & $7,7 \times 10^{3}$ & $5,2 \times 10^{3}$ & 0,19 & 0,18 & 2,31 & 1,83 & 1,84 & 5,30 \\
\hline
\end{tabular}

CBHAM - Contagem de bactérias heterotróficas aeróbias mesófilas em UFCs/g

CBHAP - Contagem de bactérias heterotróficas aeróbias psicrotróficas em UFCs/g

BVT - Bases voláteis totais em $\mathrm{mgN} / 100 \mathrm{~g}$

10. - Primeiro dia

7으. Sétimo dia

Filtração - tempo de filtração em minutos

$X$ - média

STD - Desvio Padrão

Tabela 2 - Médias de Contagem de Bactérias Heterotróficas Aeróbias Mesófilas (CBHAM) e Psicrotróficas (CBHAP), pH, Bases Voláteis Totais (BVT) e Tempo de Filtração no $1^{\circ}$ e $7^{\circ}$ dias da conservação de aves com retardo na evisceração.

\begin{tabular}{|c|c|c|c|c|c|c|c|c|c|c|}
\hline & \multicolumn{2}{|c|}{ CBHAM } & \multicolumn{2}{|c|}{ CBHAP } & \multicolumn{2}{|c|}{$\mathrm{pH}$} & \multicolumn{2}{|c|}{ BVT } & \multicolumn{2}{|c|}{ Filtração } \\
\hline & $1^{\circ}$ & $7^{\circ}$ & $1^{\circ}$ & $7^{\circ}$ & 10 & $7^{\circ}$ & 10 & $7^{\circ}$ & 1 응 & $7^{\circ}$ \\
\hline$x$ & $3,3 \times 10^{3}$ & $1,1 \times 10^{3}$ & $4,4 \times 10^{3}$ & $4,0 \times 10^{5}$ & 5,52 & 5,59 & 10,46 & 10,33 & 6,43 & 10,53 \\
\hline STD & $4,3 \times 10^{3}$ & $4,5 \times 10^{5}$ & $9,2 \times 10^{3}$ & $7,6 \times 10^{5}$ & 0,18 & 0,16 & 2,29 & 1,75 & 2,97 & 3,90 \\
\hline
\end{tabular}

CBHAM - Contagem de bactérias heterotróficas aeróbias mesófilas em UFCs/g

CBHAP - Contagem de bactéria heterotróficas aeróbias psicrotróficas em UFCs $/ g$

BVT - Bases voláteis totais em $\mathrm{mgN} / 100 \mathrm{~g}$

$1^{\circ}$ - Primeiro dia

7으 - Sétimo dia

Filtração - tempo de filtração em minutos

$x$ - média

STD - Desvio Padrão 
A análise de variância dos resultados obtidos para CBHAP e filtração, com respeito aos dias, mostrou-se significativa ao nível de $1 \%$ de probabilidade $(p<0,01)$ não mostrandose significativa $(p>0,05)$ para os tratamentos.

As comparações das médias para CBHAP e filtração realizadas através o Teste de Duncan, mostraram uma diferença significativa $(p<0,01)$, entre os dias de análise e não significativa $(p>0,05)$, para os tratamentos.

\section{Discussão e Conclusões}

Os resultados obtidos neste trabalho, conduzem a sugestões no sentido de que as Normas Higiênico-Sanitárias e Tecnológicas para Construção e Funcionamento de Matadouro de Aves (Departamento Nacional de Produção Animal, 1988), prevejam tolerância no retardo das eviscerações, uma vez que as operações de matança poderão ser interrompidas por um período de 40 minutos, sem que isto possa trazer prejuízo à cónservação das carcaças resfriadas a $3 \pm 1^{\circ} \mathrm{C}$ por um período de 7 dias.

Em relação à evisceração, os resultados mostraram-se discordantes com as afirmações de Benoff et al. (1984), Riedel (1987), devido a não observância da necessidade da evisceração ser realizada de forma imediata.

Albuquerque et al. (1979), como no presente trabalho, também não observaram alterações em aves não evisceradas, porém, trabalharam com estocagem de 96 horas à temperatura de $0^{\circ} \mathrm{C}$, diferente, desde que foi de 168 horas a $3 \pm 1^{\circ} \mathrm{C}$.

Os resultados também não se mostraram concordantes com a opinião de Asdrubali et al. (1969), que preconizam um tempo máximo de evisceração de 20 a 30 minutos, uma vez que não houve alteração significativa em um retardo de 40 minutos, na evisceração.

De acordo com os resultados obtidos neste trabalho, pode-se concluir que:

a) dentre as análises microbiológicas realizadas, a que melhor expressou o tempo de conservação foi a CBHAP;

b) dentre as provas físico-químicas realizadas (BVT, $\mathrm{pH}$ e filtração), mostrou-se satisfatória a prova de filtração, como indicativo de estado de conservação;

c) as aves submetidas a retardo na evisceração por um período de 40 minutos, apresentaram comportamento semelhante às abatidas em condições normais (sem interrupção), no período de conservação de 7 dias à temperatura de $3^{\circ} \mathrm{C} \pm 1^{\circ} \mathrm{C}$;

d) sugere-se, de acordo com as conclusões acima e com apoio na literatura compulsada, que novos estudos devam ser realizados, no sentido da avaliação das condições de conservação de carcaças de aves abatidas industrialmente, quando submetidas a períodos maiores de interrupção do processo tecnológico, do que os aqui estudados e, ain- da, estendendo tal avaliação por um período maior que 7 dias.

\section{Abstract \\ Effect of retarded evisceration on conservation of poultry (Gallus domesticus) refrigerated meat}

Were analyzed 60 poultry carcass slaughtered at an industrial plant. The carcasses were divided into two groups of 30 , in the first group a normal slaughter process was followed wile in the other group evisceration was retarded by 40 minutes.

Microbiological (CBHAM - heterotrophyc aerobic mesophylic bacterial counting and CBHAP - heterophyc aerobic psicrophyc bacterial counting) and physicochemical $(\mathrm{pH}$, filtration time and BVT - total volatile basis) determination were performed at the $1^{\text {st }}$ and $7^{\text {th }}$ days after the slaughter and the carcasses were maintained at $3 \pm 1^{\circ} \mathrm{C}$.

The mean value for the first day $\left(1^{\text {st }}\right.$ and $2^{\text {nd }}$ groups respectively) were: $5,1 \times 10^{3} \mathrm{UFC} / \mathrm{g}$ and $3,3 \times 10^{3} \mathrm{UFC} / \mathrm{g}$ for CBHAM; $6,3 \times 10^{3} \mathrm{UFC} / \mathrm{g}$ and $4,4 \times 10^{3} \mathrm{UFC} / \mathrm{g}$ for CBHAP; $\mathrm{pH}$ 5.59; and 5.52; filtration time 6.77 minutes and $6.43 \mathrm{~min}$,; and $10.38 \mathrm{mg} \mathrm{N} / 100 \mathrm{~g}$ and $10.46 \mathrm{mgN} / 100 \mathrm{~g}$ for BVT. In the $7^{\text {th }}$ day the mean values were respectively: $2.1 \times 10^{4} \mathrm{UFC} / \mathrm{g}$ and $1.1 \times 10^{5} \mathrm{UFC} / \mathrm{g}$ for CBHAM; $2.5 \times 10^{5} \mathrm{UFC} / \mathrm{g}$ and $4.0 \times$ $10{ }^{5} \mathrm{UFC} / \mathrm{g}$ for CBHAP; the $\mathrm{pH}$ were 5,51 and 5.59; the filtration times were 10.13 minutes and 10.55 minutes; and the BVT $10.48 \mathrm{mgN} / 100 \mathrm{~g}$ and $10.33 \mathrm{mgN} / 100 \mathrm{~g}$. The variance analyses showed significant differences between the $1^{\text {st }}$ and $7^{\text {th }}$ days for CBHAP and filtration times for both groups. There was no significant differences between the two treatments for the parameters analyzed.

Key words: poultry meat, retarded evisceration, shelf-life.

\section{Referências Bibliográficas}

ALBUQUERQUE, A.J.D., SANTOS, A.F., SCHNEIDER, I. Comparação entre Frangos Eviscerados e não Eviscerados Conservados a Frio. Revista do Centro de Ciências Rurais da Universidade de Santa Maria, v. 9, n. 1, p. 15-18, 1979.

ASDRUBALI, M., STRADELII. Los mataderos. Trad. por A de Joana Svedon. Zaragoza, Acribia, 1969. 267p

BARTELS, H. Inspeccion Veterinária de la Carne. Trad. por Jaime Esain Escobar. Zaragoza, Acribia, 1971. 491p.

BENOFF, F.H., HAM, D., HUDSPETH, J.P., LYON, C.E. Meat Yield Comparisions of Hot Cut-Up Noneviscerated Versus Eviscerated Immersion Chilled Broilers: Poultry Science, v. 63, n. 3, p. 507-509, 1984.

Departamento Nacional de Produção Animal (Brasil). Departamento de Inspeção de Produtos de Origem Animal. Portaria nº 4, junho 1988. Inspeção de carnes: 2. Aves. Brasília, 1988. 54p.

Departamento Nacional de Produção Animal (Brasil). Secretaria Nacional de Defesa Agropecuária Laboratório Nacional de Referência Animal (LANARA). Portaria no 001, outubro 1981. Métodos Analíticos Oficiais para Controle de Produtos de Origem Animal e seus Ingredientes. Brasília. 1981

RIEDEL, G. Controle Sanitário dos Alimentos. São Paulo: Loyola 1987, 445p. 